\title{
Continuous infusion of papaveretum for relief of postoperative pain
}

\author{
S. K. SAHA \\ B.Sc., F.R.C.S.E. \\ Department of Surgery, Montagu Hospital, Mexborough, Yorkshire
}

\begin{abstract}
Summary
Postoperative analgesia, once established initially by the titration method, is sustained with a flexible regime of papaveretum, infused continuously with a portable syringe pump. The initial analgesic requirement (IAR) for titrating the pain threshold level, was between 4 and $10 \mathrm{mg}$ of papaveretum and the maintenance dose between 1 and $1.66 \mathrm{mg} / \mathrm{hr}$ for the first $24 \mathrm{hr}$ and between 0.83 and $1 \mathrm{mg} / \mathrm{hr}$ for the second $24 \mathrm{hr}$. There was no significant association between IAR and the maintenance dose $(P<0.2)$ nor was there any correlation between the maintenance dose, body weight, age, sex or nature of operations. The results in 70 patients are encouraging.
\end{abstract}

\section{Introduction}

Despite various approaches to the administration of narcotics, the management of postoperative pain remains unsatisfactory (Morrison, Loan and Dundee, 1971; Chakravarty, 1979; Phillips and Vickers, 1979). The standard practice of prescribing a narcotic for i.m. injection at regular intervals, based upon the age, sex, body weight and nature of operation is a rigid approach that often fails to provide satisfactory relief of pain.

Intermittent i.v. administration of analgesics is, in some ways, a more satisfactory approach (Chakravarty et al., 1979) but its maintenance for more than a few hours is difficult. However, since the advent of a portable syringe pump, it has been possible to infuse narcotics continuously and safely. The principle involved in this study, was to maintain the continuous analgesia that is comparable to the individual pain threshold level. To achieve this objective the initial pain threshold level, once established by a titration method, was sustained for 40-50 hr with a flexible regime of a maintenance dose of papaveretum. A prospective study of this new concept in the treatment of postoperative pain is now reported.

\section{Materials}

Between October 1978 and May 1979, 70 patients (36 male and 34 female) aged between 20 and 81 years, and with body weights between 44 and $95 \mathrm{~kg} \frac{\mathrm{O}}{\mathrm{C}}$ were included in this study. Six of them had had 3 . emergency laparotomies through a paramedian of incision for either perforated duodenal ulcers or $\sigma$ large bowel obstruction. Of the remaining $64 \mathrm{\omega}$ patients, upper paramedian or midline incisions 8

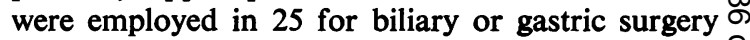
and lower paramedian incisions in $\mathbf{3 1}$ for colonic $\frac{5}{5}$ surgery. Apart from these, a variety of other operations were performed in the other 8. All were $z$ operated upon by the author or 2 other surgeons.

\section{Method}

The initial analgesic requirement (IAR) w established as soon as the patients started feeling $\stackrel{\infty}{\infty}$ pain on recovery from general anaesthesia. The was done by injecting papaveretum $(20 \mathrm{mg}$ in $20 \mathrm{mt}$ normal saline) into a vein at the rate of $1 \mathrm{mg}$ of papaveretum/min until the pain was relieved; although it is possible safely to administer $4 \mathrm{mg}$ of papaveretum immediately and then wait $5 \mathrm{~min}$ to $\stackrel{\mathbb{Q}}{\varrho}$ observe its effect before administering a further $\overrightarrow{\overrightarrow{0}}$ amount at the rate of $1 \mathrm{mg} / \mathrm{min}$. The criteria for a 3 satisfactory response were (i) the relief of pain $\vec{F}$ admitted by the patient; (ii) deep inspirations; (iii) a respiratory rate of between 18 and $22 / \mathrm{min}$; 항 (iv) return of normal skin colour; (v) evidence 3 . of relaxation on the face (i.e. disappearance of $\dot{\sigma}$ wrinkles over the forehead or between the eyebrows).

The administration of the narcotic was dis- o continued if the patient fell asleep, felt nauseated $₹$ or if the respiratory rate fell below $16 / \mathrm{min}$.

The initial analgesia, once achieved by the titration method, was maintained for a period of $40-50 \mathrm{hr}$ by continuous 'topping up' with a portable syringe $N$ pump known as a 'driver syringe' (M.S. 16 Pye Dynamics Ltd). The digital clock of the instrument $\tilde{O}$ regulates the rate of continuous infusion of drug per $\underset{\omega}{N}$ hour from the syringe, connected to the forearm vein directly or the transfusion set of other i.v. 0 therapy. The maintenance dose for sustaining the $\overparen{\varnothing}$ continuous analgesia was $1 \mathrm{mg}$ of papaveretum $/ \mathrm{hr} \stackrel{\text { ? }}{\rightarrow}$ for the first $20-24 \mathrm{hr}$ and $0.83 \mathrm{mg} / \mathrm{hr}$ for the second ${ }^{\circ}$ 20-24 hr. 
To implement this regime, the digital clock of the driver syringe, filled with papaveretum $20 \mathrm{mg}$ in $20 \mathrm{ml}$ normal saline (i.e. equivalent to $60 \mathrm{~mm}$ in length) is set up to run at the rate of $1 \mathrm{mg} / \mathrm{hr}$ (i.e. $3 \mathrm{~mm} / \mathrm{hr}$ ) for $20 \mathrm{hr}$. In some cases, the dose may be increased to $1.33 \mathrm{mg}$ or $1.66 \mathrm{mg} / \mathrm{hr}$ for recurrence of pain or discomfort, by adjusting the digital clock from 3 to 4 or $5 \mathrm{~mm} / \mathrm{hr}$ respectively. For each successive $12 \mathrm{hr}$ after the first $20-24 \mathrm{hr}$, papaveretum $10 \mathrm{mg}$ in $20 \mathrm{ml}$ normal saline, as in the first operation, is infused at the rate of $0.83 \mathrm{mg} / \mathrm{hr}(5 \mathrm{~mm} / \mathrm{hr})$. It can be increased to $1 \mathrm{mg} / \mathrm{hr}$ by changing the digital clock from 5 to 6 . A reasonable time (1-2 hr) should be allowed for monitoring the response to the increased dose before any further change in dose is contemplated. The increased dose should be reduced to the basic maintenance dose 6-8 hr later, or sooner if the respiratory rate falls below $16 / \mathrm{min}$.

An hourly observation chart, especially designed for this study, which incorporated blood pressure, pulse rate, respiratory rate, vomiting, nature of pain, state of mind and hourly dose, was maintained in every case. Such a chart is invaluable when reviewing the clinical condition of the patient and reminds the nurses and the doctors of when and how much the hourly dose had been increased and how much the patient's demand for analgesia is consistent with the observations recorded in the chart.

\section{Results}

The IAR was in the range of 4-6 mg (mean
$5.3 \mathrm{mg}$ ) in 38 and $7-10 \mathrm{mg}$ (mean $8.3 \mathrm{mg}$ ) in 32 patients. No obvious association with age, sex and body weight was observed in the 2 groups. but there was a difference in the IAR between upper and lower abdominal incisions. It was in the higher range $(7-10 \mathrm{mg})$ in 15 of 26 upper abdominal (paramedian/midline) incisions $(58 \%$ ) as compared with 15 of 36 lower abdominal incisions (42\%).

The maintenance dose with $1 \mathrm{mg}$ of papaveretum/ $\mathrm{hr}$ for the first 20-24 hr was not adequate for the satisfactory relief of pain in $50 \%$ of the patients. It was in the range of $1.33-1.66 \mathrm{mg} / \mathrm{hr}$ in 35 of 70 patients, required within $6 \mathrm{hr}$ of the commencement of therapy, although they did not need this increased dose after $8 \mathrm{hr}$. There was no significant relationship between IAR and the maintenance dose in all patients $\left(\chi^{2}=2.07, P<0.2\right)$. Sixteen of 38 and 19 of 32 patients whose IAR was in the range of 4-6 mg for the first, and 7-10 $\mathrm{mg}$ for the latter group, required a maintenance dose above $1 \mathrm{mg}$ of papaveretum/hr within the first $6 \mathrm{hr}$ of commencing therapy, representing an incidence of $46 \%$ and $54 \%$ respectively. By contrast, the incidence of cases with lower abdominal incisions requiring more than $1 \mathrm{mg}$ of papaveretum/hr was $48 \%$ and $73 \%$ as against that of $45 \%$ and $47 \%$ respectively with upper abdominal incisions of the corresponding IAR groups (Fig. 1).

Although there was no sex relationship in the IAR, the data in Fig. 2 suggest more tolerance in male than in female patients, irrespective of age, body weight and nature of operation.

There was very little difference in the maintenance

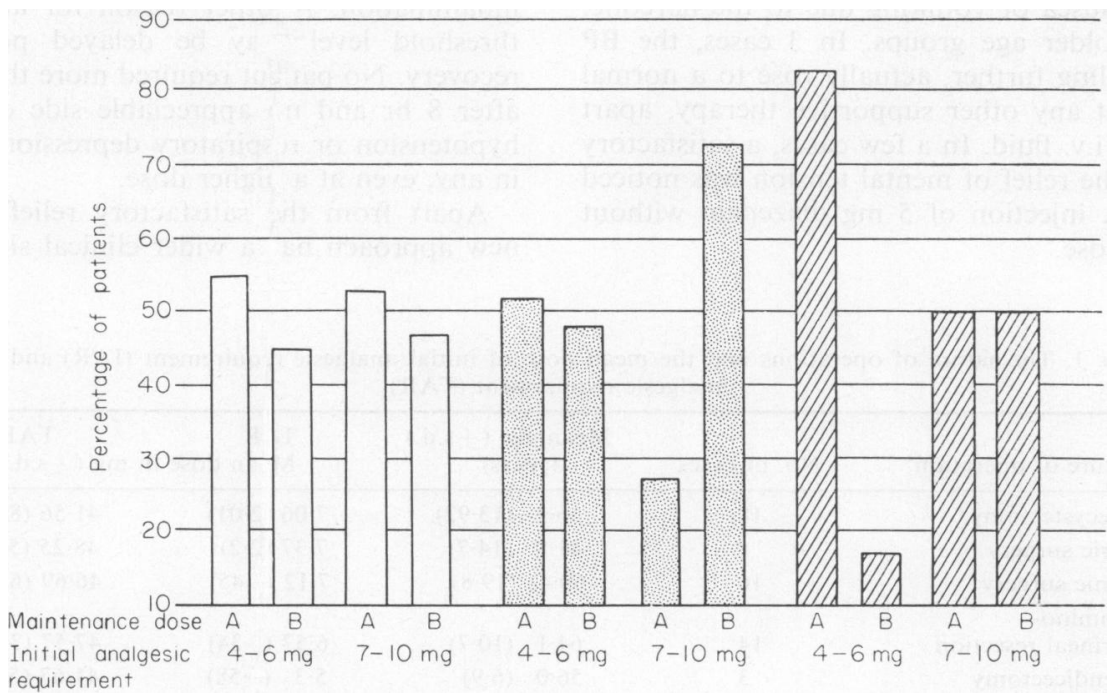

FIG. 1. The relationship between the analgesic requirements and the sites of incision. $A=1 \mathrm{mg} / \mathrm{hr} ; \mathrm{B}=1-1.66 \mathrm{mg} / \mathrm{hr}$; $\square=$ upper abdominal incisions; $: 0$ =lower abdominal incisions; $\mathbb{Z}=$ miscellaneous incisions. 
dose for the second period of 20-24 hr after operation. It was $0.83 \mathrm{mg} / \mathrm{hr}$ in 59 and $1 \mathrm{mg} / \mathrm{hr}$ in 11 patients (Fig. 2). The mean dose of IAR and total analgesic requirement (TAR) of papaveretum for different types of operations is shown in Table 1.

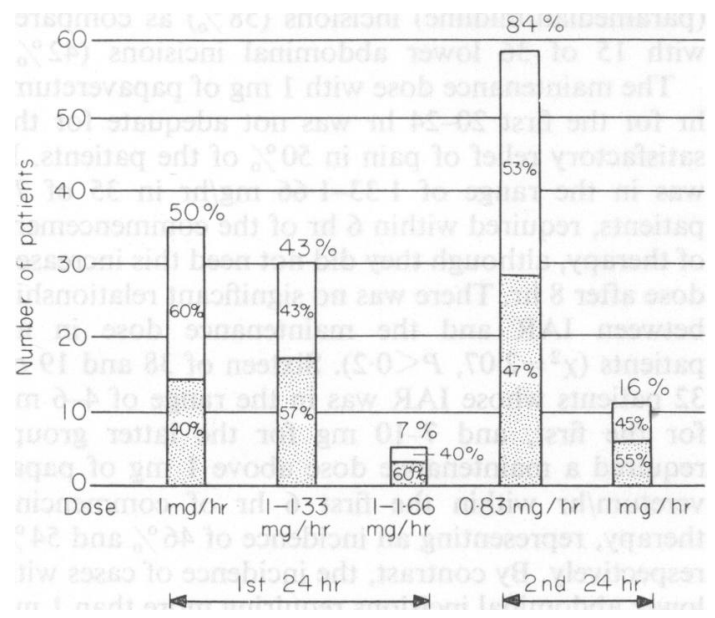

FIG. 2. The difference in dose between 36 male $(\square)$ and 34 female (图) patients.

In most cases, the respiratory rate was between 18 and $22 / \mathrm{min}$. In one case, the maintenance dose had to be reduced from 1.66 to $1 \mathrm{mg}$ when the rate of respiration fell to $16 / \mathrm{min}$. A rise in the respiratory rate for any other reason should not always be an indication for increasing the dose, provided the patient remains pain free. There was no case of a fall in BP, nausea or vomiting due to the narcotic, even in the older age groups. In 3 cases, the BP instead of falling further, actually rose to a normal range without any other supportive therapy, apart from routine i.v. fluid. In a few cases, a satisfactory response to the relief of mental tension was noticed after the i.m. injection of $5 \mathrm{mg}$ diazepam without altering the dose.

\section{Discussion}

Fry and Deshpande (1977) disputed the view that $c$ the pharmacological dose of a narcotic is mainly dependent on the body weight and age, and the observation of this study bears them out. The primary objective of performing the titration was to $\frac{\overline{\underline{N}}}{\bar{n}}$ establish a level of initial analgesia with papaveretum? without producing mental cloudiness. This may be $\varrho$ regarded as the individual pain threshold level to the noxious stimuli arising from the wound. Thelevel of analgesia, once established, was maintained ${ }_{-}^{\circ}$ by a continuous infusion of papaveretum with $\mathrm{a}_{\boldsymbol{\omega}}$ flexible dose regime over a period of $48 \mathrm{hr}$. There appeared to be no significant association betweeno IAR and maintenance dose $(P<0 \cdot 2)$, although 3 . the IAR was used as a guideline in another study (Fry and Deshpande, 1977) for prescribing theog dose of papaveretum for i.m. injection at regularw intervals. It is unlikely to have provided continuous ${ }_{\infty}^{\circ}$ analgesia in those patients, for the pain threshold $\odot$ level is not always a constant feature and varies with? the change in stimuli. In the present study, the IAR varied between 4 and $10 \mathrm{mg}$ compared with 6-30 $\mathrm{mg} Z$ in that of Fry and Deshpande. The higher IAR required for the upper abdominal incision as $\frac{3}{6}$ compared with the lower abdominal incision may be attributed to the movements of chest wall ag $\mathrm{d}_{\overrightarrow{0}}$ diaphragm which subject the wound to moseog disturbance. There appeared to be no obviof reason for requiring more than $1 \mathrm{mg}$ of papaveretum $\overrightarrow{\mathrm{m}} / \overrightarrow{0}$ $\mathrm{hr}$ in about $50 \%$ of the patients. It is postulated that the change in pain threshold level in these cases waso influenced by raised intraperitoneal tension or waso associated with the extent of tissue damage and$\stackrel{\mathbb{Q}}{\varrho}$ inflammation. Another reason for an altered pain $\overrightarrow{\vec{O}}$ threshold level may be delayed post-anaesthetic 3 recovery. No patient required more than $1.66 \mathrm{mg} / \mathrm{hr}$ after $8 \mathrm{hr}$ and no appreciable side effects such as. hypotension or respiratory depression were noticedo in any, even at a higher dose.

Apart from the satisfactory relief of pain, this new approach has a wider clinical significance. An?

TABLE 1. The nature of operations and the mean dose of initial analgesic requirement (IAR) and total analgesic requirement (TAR)

\begin{tabular}{|c|c|c|c|c|}
\hline \multirow{2}{*}{$\frac{\text { Nature of operation }}{\text { Cholecystectomy }}$} & \multirow{2}{*}{$\frac{\text { No. of cases }}{18}$} & $\underset{\text { (years) }}{\text { Mean age }( \pm \text { s.d.) }}$ & \multicolumn{2}{|c|}{$\begin{array}{lr}\text { IAR } & \text { TAR } \\
\text { Mean dose in mg }( \pm \text { s.d. })\end{array}$} \\
\hline & & $56.2 \quad(13.92)$ & $7.06(2.01)$ & $41 \cdot 56(8 \cdot 6)$ \\
\hline Gastric surgery & 8 & $41 \cdot 8 \quad(14 \cdot 7)$ & $7 \cdot 37(2 \cdot 2)$ & $48 \cdot 25(5 \cdot 87)$ \\
\hline Colonic surgery & 16 & $60.4 \quad(19 \cdot 8)$ & $7 \cdot 12(1 \cdot 45)$ & $46.69(6.42)$ \\
\hline $\begin{array}{l}\text { Abdomino- } \\
\text { perineal resection }\end{array}$ & 14 & $64 \cdot 1 \quad(10 \cdot 7)$ & $6.57(1.34)$ & $47 \cdot 57(3 \cdot 13)$ \\
\hline Appendicectomy & 3 & $56.0 \quad(6.9)$ & $5 \cdot 3 \quad(0.58)$ & $41 \cdot 67(5 \cdot 78)$ \\
\hline Haemorrhoidectomy & 3 & $37 \cdot 7 \quad(6 \cdot 1)$ & $6 \cdot 3 \quad(3 \cdot 2)$ & $44 \cdot 00(4 \cdot 00)$ \\
\hline Other & 8 & $58.8 \quad(13.9)$ & $6 \cdot 37(1.06)$ & $37.5 \quad(14.45)$ \\
\hline
\end{tabular}


increased urinary output $(1000-1200 \mathrm{ml} / 24 \mathrm{hr})$ was noticed in a large number of patients in this series, probably contributed to by a steady normal BP and satisfactory relief of pain. Furthermore, physiotherapists noticed a considerable improvement after increasing the hourly dose before the chest physiotherapy was carried out.

The continuous i.v. infusion of pethidine (Church, 1979) appears to be an alternative choice of drug, but problems may arise in the management of other i.v. therapy, if the infusion of pethidine in sodium lactate solution, as suggested by Church, is administered at the rate of $0.5 \mathrm{ml} / \mathrm{kg} / \mathrm{hr}(900 \mathrm{ml} / 24 \mathrm{hr}$ for a body weight of $75 \mathrm{~kg}$ ). In contrast, little has to be done to the driver syringe, once it has been set up. It does not interfere with the daily fluid balance or i.v. therapy. Any adjustment of maintenance dose for recurrence of pain can be undertaken by the nursing staff on the instruction of the doctors concerned. This new approach has met most of the author's desired objectives in the management of postoperative pain.

\section{Acknowledgment}

I wish to thank the consultant anaesthetists and the surgeons, particularly $\mathrm{Mr}$ B. C. H. Luker, F.R.C.S. and Mr A. L. Black, F.R.C.S., for their encouragement in my work. I am also grateful to Dr G. D. Powell, consultant pathologist, for his help in writing this paper. My appreciation is also due to Sister Hill and Sister Chapman for their participation in my work and to $\mathrm{Mr}$ G. B. Farmer for medical illustrations.

\section{References}

Chakravarty, K., Tucker, W., Rosen, M. \& Vickers, M.D. (1979) Comparison of buprenorphine and pethidine given intravenously on demand to relieve postoperative pain. British Medical Journal, 2, 895.

ChURCH, J.J. (1979) Continuous narcotic infusions for relief of postoperative pain. British Medical Journal, 1, 977.

Fry, E.N.S. \& DeshPande, S. (1977) Postoperative analgesia by titration of papaveretum. British Medical Journal, 2, 870.

Morrison, J.D., LoAN, W.B. \& DundeE, J.W. (1971) Controlled comparison of the efficacy of fourteen preparations in the relief of postoperative pain. British Medical Journal, 3, 287.

Phillips, G. \& Vickers, M.D. (1979) Nefopam in postoperative pain. British Journal of Anaesthesia, 51, 961. 